\title{
Parametric Design in the Course of Computer-Aided Industrial Design
}

\author{
Xiaofei Lu ${ }^{a}$, Silu Jiab \\ Xi'an University of Science and Technology, Art College, Xi'an, China \\ 23700637@qq.com, ${ }^{a} 1047541359 @ q q . c o m$
}

Keywords: computer-aided industrial design, parametric design, teaching model

\begin{abstract}
With the development of science and technology, the society attaches great importance to the cultivation of professionals in industrial design and other fields. The thesis analyzes the training direction of industrial design talents and the orientation of the demand for talents in the future. It introduces the general situation of the current course of computer-aided design, the problems it faces and the direction to be adjusted. This paper discusses the significance of parametric design in industrial design, proposes that parametric design and rapid prototyping should be combined with the course of computeraided design to improve students' learning efficiency and enhance their practical ability with the aim at developing high-quality expertise that meets modern standards and social needs.
\end{abstract}

\section{Introduction}

In industrial design or product design, the designer always needs to modify the product model repeatedly in accordance with the customer's or subjective needs; sometimes he or she needs to continually modify and filter in different plans. And it may increase design and time costs without the help of computers. Computer-aided industrial design is an inevitable trend in the development of society and education. It not only opens up the multi-platform and multi-presentation of modern design, but also greatly shortens the time of cycle and shaping of design research and development. In business development, it promotes integration and communication between design department and other departments, and modification becomes more convenient and efficiently. Therefore, computeraided design (CAD) has become an important part of talent education.

However, traditional course system of computer-aided design has been unable to cope with the diversified and short-cycle needs in modern society. With an increasing widely application of parametric modeling technology in computer-aided architectural design, parametric design has a bright prospect and rapid development. It has yielded plenty of results in a short time. There have been many practical applications of parametric design in existing excellent buildings. Therefore, parametric design should be combined with the computer-aided industrial design scientifically and reasonably. Each design element should be set as a variable, and the information model of the design 
object should be constrained by the parameters. By controlling a number of parameters to obtain qualified design works, the scientificity, reliability and efficiency of the design process are greatly enhanced.

\section{Computer-Aided Design}

Jing ping Sun [1] mentioned that computer-aided design is a method and technology that uses computer hardware and software systems to assist people in designing products or projects. It is a new technology for multidisciplinary comprehensive application, becoming a compulsory course for the cultivation of industrial design professionals and the promotion of students' professional ability. Computer-aided design (CAD) is the application of computer in industrial product design. On the one hand, it makes up for the deficiency of students' hand-painted renderings, and on the other hand, it improves efficiency.

The field of automobile design is the first to use computer-aided design (CAD) technology, which is an important part of many advanced manufacturing technologies. It is used to design the shape and structure of a car. After its later development, it expanded to the field of design drawings, manufacturing analysis, simulation analysis as well as machinery industry and construction, promoting the development of related technology. Because the speed and accuracy of computer operation and the wide range of data query, the design speed is greatly improved, which contributes to facilitate the optimization of the design in the later stage, shorten the product development cycle, reduce the product cost, improve the product design quality, enhance the product competitiveness and reduce the scrap rate.

\section{Research Status}

\subsection{Students Source of Industrial Design}

Industrial design is a comprehensive discipline that combines the basic quality of engineering machinery design and art culture. As a result, the industrial design education students are divided into two types: one is science and engineering students; the other is art students. The former have solid foundation in mathematics, experiments, materials technology, machinery manufacturing, etc. and they are more acceptable for rational industrial design, but their aesthetic ability and shaping innovation ability are weak; the latter have received professional training of art quality, having acquired the technical knowledge and appreciation ability of designing color, shape and structure, which is closer to the expression of personal intention, but lacks logic and rational thinking.

Previously, industrial design only recruits students of science and engineering. Cixian Lu [2] introduced the "Non-art undergraduate majors enrolled by art majors in the general colleges and universities" which are issued by the Ministry of Education in 2010, clearly stated that the industrial design majors of 127 colleges and universities can not only recruit students of science and engineering, but also recruit art student, analyzed the differences between the two types in the teaching system and professional characteristics, believed that a scientific and practical teaching curriculum system should be established, combining the strengths of two types of students with the aim at cultivating professional and comprehensive industrial designer.

\subsection{Course Design and Problem Analysis}

Industrial design is an interdisciplinary subject that covers product design, home design, transportation design, display and device design and other fields. The computer-aided design course 
is aimed at training students' software operation ability and different design expressions, learning image processing, design, modeling, rendering, product effect display and so on. The professional knowledge and design techniques that need to be mastered in different fields are different, itis the numerous software that cause the complexity of the curriculum.

Due to the replacement of software versions, the increase of new functions, the wide variety of software, and the employment of students, the current colleges and universities face the teaching problems such as curriculum refinement, curriculum orientation and practicality in professional curriculum arrangement.

- The software version changes quickly, new function increases, and several software cooperate with the auxiliary use. In such cases, the teaching system is forced to adjust in accordance with the employment development which resulted in a non-mature teaching system.

- There are many kinds of software, but practical application is limited. It is difficult for students to use multiple software in a comprehensive way.

- Short course time leads to the lack of students' self-thinking time and the imperfect of students' evaluation system. Under these circumstances, students' enthusiasm decreases, learning efficiency and learning autonomy decreases, and the teaching effect is affected.

\section{Parametric Design and Rapid Prototyping}

\subsection{The Concept of Parametric Design}

In the modern related field, parametric design is to parameterize design elements and design links, define the design thinking process by the use of parameters, and generate design schemes through parameter combination. The core of computer operation is algorithm in which each parameter controls the result. It is a new scientific design method that if you change one of the parameter values, the design result will change accordingly. Driven by the modern design, designers began to pay attention to the logic and controllability of design. According to the corresponding parameter adjustment, new design results can be generated, and the design is more rigorous and diversified. Parametric design is on the one hand the parameterization of the design method, on the other hand, is the parameterization of the design concept. It cannot be confused that it is the innovation of technology and the transformation of the design concept.

In architectural design, parameterization focuses on skin construction and functional diagram. In industrial design, it focuses on modeling and CNC machining, as well as complex A-level surface modeling. It considers parameters as variables or influencing factors. After the establishment of product data model, the parameter variables are limited. The parametric model represents the geometric constraints and engineering constraints of the part graphics. The geometric constraints are the constraints of structure and size, and the engineering constraints are the logical relationships of values. The designer then can rigorously adjust, screen, test and feedback the design process in accordance with the logical structure of the product model set by the materials and processes in postproduction and processing.

\subsection{Parametric modeling technology}

Parametric modeling software platforms are generally divided into the category of humancomputer interaction, the category of visual programming, and the category of pure scripting.

Human-computer interaction software such as CATIA is a kind of interaction between human and computer hardware and software. The designer can draw the design model through the software 
design interface, and adjust the design process of variable screening according to feedback. The software, with high popularity, provide the renderings of the design results visually which is easy to modify the design of shape.

For the visual programming software such as Grasshopper, with the design parameters regulated, the design results will change according to a certain property. Regardless of any programming expertise, it only requires a data input at the node, through which a designer is able to adjust the dynamic model and observe the regular pattern of morphological changes so that the results can be screened and optimized and then put into production, greatly shortening the design cycle [1].

Pure script editing software such as Solid Works, Rhino, etc., comes with parameterized script editing program, using complex script programming or embedded application interface to support secondary development software, which is of a relatively higher technological threshold and is difficult for designers in practice since it needs professional quality.

- Pro/Engineer: The earliest parametric design software is mainly used in industries of household appliances daily necessities, consumer electronics and engine design.

- UG and CATIA: UG mainly serves for product modeling and processing, which is applied in mechanical design and product design. It covers the entire product life cycle and is suitable for more complex environment of curved surface. CATIA mainly focuses on surface modeling. Due to the convenient modification ability of CATIA throughout the product cycle, especially the later modification, users can easily and repeatedly modify the product, which is widely used in complex surface of automobiles, airplanes, ships, etc. Therefore, the two software are commonly seen in the design and manufacture of high-end products such as manufacturing and aerospace.

- Solid Works: Solid Works is used in machine manufacturing and product design. It can be employed for the design of using part modeling and tools and also for the redevelopment by using the embedded application interface [4]. With more precision, the software is much powerful in simulation, easy to learn and use, and of technical innovation, which can quickly create three-mode models and be exported in 2D drawings, providing different design solutions, reducing errors in the design process and improve products quality.

- Rhino and Grasshopper: Rhino is the most commonly used software for industrial design, enabling rapid modeling and is therefore widely used by industrial designers and architects. Grasshopper, designed with high efficiency and requiring no programming and scripting expertise, is a model tool used with Rhino to decompose each logical process of Rhino and used separately when programming languages are presented in the form of nodes and squares. The tool applies parameter slider storing information to change the value and produce a complex parametric model. Thanks to the powerful operator, it is suitable for more complicated engineering design and, with its refined storage mode, can generate new models by program algorithm.

\subsection{New Processing and Modeling Technology}

With the parametric model design completed, the STL format can be output. After slicing the model in the machine software, 3D printing or CNC machining equipment such as CNC can be used to make the solid model. The extensive application of numerical control technology, as the development tendency, plays a decisive role for the degree of digital competence in manufacturing industry, realizing information integration and synthesis, improving competitiveness and generating economic benefits. 


\subsubsection{D printing}

3D printing (as shown in Fig. 1) is a rapid prototyping technology. Based on the digital model, the entity can be printed layer by layer using the adhesive materials such as powdered metals or plastics [5]. With the development of technology, it has gradually replaced the mode of traditional manufacturing industry. 3D printing has high precision and can print out model details in a fine manner. Compared with traditional methods such as stamping and etching, it can create model more quickly. 3D printing model (as shown in Fig. 2) is a kind of additive manufacturing. Generally, it can use all kinds of metal or non-metal and composite materials to overlay quickly, with timeefficiency and diversity of materials. Large model needs to be divided into multiple parts that are individually printed and glued to avoid problems such as damage of large model parts, excessive supports and waste of materials. Design and manufacture of solid models: three-dimensional software modeling, equipping printers with hierarchy-sliced software, printing models, painting and polishing, finishing and coloring, etc.

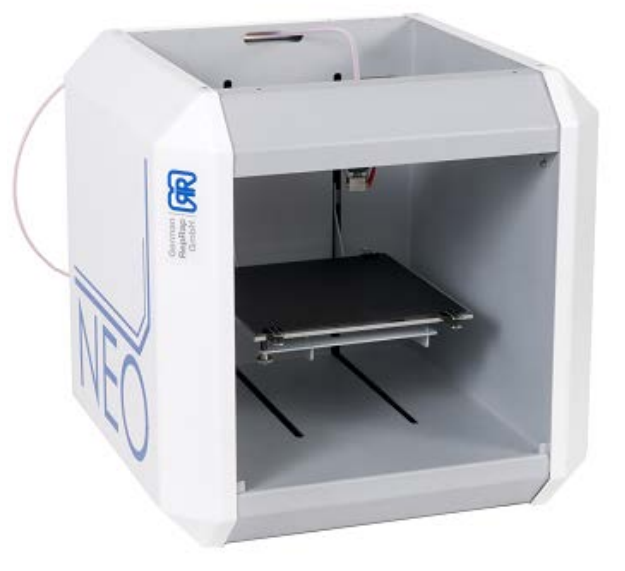

Fig 1 NEO home 3d printer

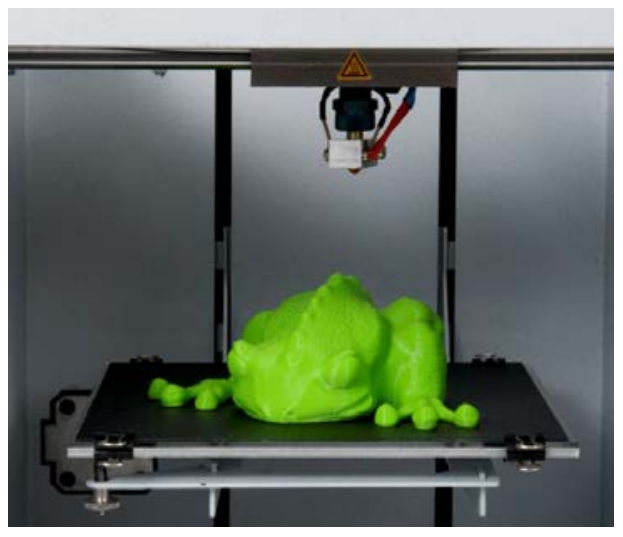

Fig 2 The model printed by NEO

\subsubsection{NC Machining}

Numerical-control machine tool (as shown in figure 3) is different from traditional machining. Instead of traditional machining or semi-mechanical and semi-manual machining, it is an automatic machine tool operated by a control system. NC machine tool is controlled by programmed computer, suitable for machining complex and high precision parts. It is characterized by high automation, 
short production cycle, high precision and stable quality.

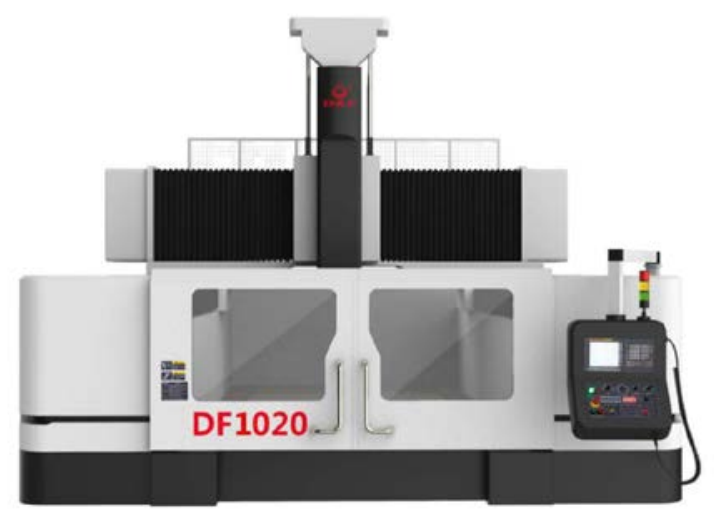

Fig 3 De Feng precision CNC machine tool

\section{Parametric Design Curriculum setting}

Parametric modeling software platforms are generally divided into the category of humancomputer interaction, the category of visual programming, and the category of pure scripting.

It is suggested to popularize relevant courses in Chinese universities, set up special parametric design courses or emphasize parametric design in the design courses, in combination with model manufacturing and processing so as to improve the ability of rapid design and model generation. In particular, for students of art, traditional courses only require students to complete the design and modeling of industrial products, without emphasizing the importance of parameterization in design ideas and design methods. The design process is lack of rigorousness and rationality, which leads to the monotony of students' thinking of design methods, resulting in lack of innovation.

After the course configuration is added with parametric design and rapid prototyping, the students can develop the logic of design thinking and design with rigorous thinking, with which they can repeatedly test and revise the given design resulting from creativity and inspiration that are expected to be stimulated continuously, enabling them quickly create entities and greatly improving the efficiency and practical application of the course. Secondly, it arouses students' enthusiasm, stimulates their interest in learning and enables them to experience diverse morphological changes brought about by parameter and data setting, leading to a developed design thinking and improved operational ability so that students can review the design process with solid models and make up for deficiencies.

Moreover, it is beneficial to course examination and assessment. Based on the complete design process, teachers can identify students' problems in time, such as the rationality of the design concept, the integrity of the design, the diversity of the design thinking or any possible vulnerability, etc. In this case, teachers can correct and adjust the teaching mode in the first time to realize efficient use of classroom time and facilitate the integration of knowledge.

Computer-aided parametric design and rapid prototyping technology serve as a trend and direction in the future, which comply with the employment development and demand of students and meanwhile solve the problem of the lag time of school software update.

\section{Conclusion}

The author analyzes the feasibility of parametric industrial design. Via the adjustment of computer-aided curriculum orientation, it is hoped such curriculum can motivate students' learning 
interest, enhance their professional quality and practical ability. However, with the development of social industrial design, it is also necessary to follow the pace of scientific and technological development to improve and supplement the curriculum in the future.

\section{References}

[1] JinpingSun. Current Situation and Development of Computer-Aided Design [J]. Journal of Beijing City University,2003(04):82-86.

[2] CixianLu. The Training System of Industrial Design Talents Based on Two Types of Students [J]. Research in Higher Education of Engineering, 2011(06): 146-149+154.

[3] ZongmingLu, YixuanLi. Research on Parametric Design of Luminaire Based on Grasshopper Plug-in[J]. Packaging Engineering, 2018, 39(18): 209-213.

[4] JingkuiLi, YingyiJing. Parametric Design Based on SoildWorks[J]. Journal of Tianjin University of Technology, 2009, 25(04): 26-28.

[5] QingLi, Qing Wang. 3D Printing: An Emerging Learning Technology [J]. Journal of Distance Education, 2013, 31(04): 29-35. 